Nous traduirions en mangeant, en tournant, en dormant en latin par: "cum manducetur, ubi tornatur (latin class. vertitur), dum dormitur", ou bien par le gérondif impersonnel, en suivant l'usage du latin postclassique.

Quand A. Stimming ${ }^{1}$ ) nous cite l'exemple suivant: Jo li ferai crever les II iex en forant (Jerus 6626), en disant que le cas où le sujet du gérondif est "on" se présente rarement, et en donnant l'explication: "pendant qu'on fore", et quand $\mathrm{P}$. Klemenz ${ }^{2}$ ) nous fournit l'exemple: Item en allant outre en montant ung peu, a senestre partie a une chapelle de Saint Marc, nous ne voudrions voir dans ces gérondifs-là également qu'un simple circonstanciel, sans que l'on ait besoin d'un sujet pour l'action représentée de façon impersonnelle. Le gérondif, tout en gardant sa valeur verbale, ne fait fonction dans la phrase que comme adverbe.

Amsterdam.

B. H. J. WEERENBECK.

\title{
OVER DEN SAMENHANG DER KLANKVERSCHUIVINGEN IN DE GERMAANSCHE DIALECTEN.
}

Sedert Jacob Grimm de ontdekking van Rask uitwerkte, de onder deze ontdekking vallende verschijnselen onder één naam samenvatte en dienzelfden naam ook op analoge verschijnselen in het Hoogduitsch toepaste, heeft de traditie bestaan, de Germaansche en de Hoogduitsche klankverschuiving uit gemeenschappelijke gezichtspunten te beschouwen en de tweede althans tot op zekere hoogte als eene herhaling der eerste aan te merken. Minder is de aandacht er op gevallen, dat het consonantisme van het Skandinavisch en vooral van het Deensch een reeks eigenaardigheden vertoont, die voor de beoordeeling van de Oergermaansche en de Hoogduitsche klankverschuiving van het grootste belang zijn. Ik kies deze Skandinavische verhoudigen tot uitgangspunt der volgende studie en zal daarvan een kort exposé geven; de Oergermaansche en Hoogduitsche toestanden mag ik als bekend vooronderstellen.

De Hoogduitsche en de Skandinavische verschuiving hebben tegenover de Oergermaansche algemeene punten van overeenstemming, wier oorzaak in de chronologie gelegen is. Deze zijn: 1. Het uitbreidingsgebied is beperkter; niet alle Germaansche dialecten hebben er deel aan. 2. Er is verschil in de geographische uitbreiding der afzonderlijke verschijnselen; sommige consonanten zijn over een grooter geographisch gebied verschoven dan andere. 3 . Er is verschil in intensiteit, zoodat sommige consonanten niet verschoven zijn, andere in bepaalde omstandigheden, andere regelmatig, sommige ook naar gelang van de plaats in verschillenden graad. Een verder verschil is gelegen in het punt van uitgang. Terwijl aan de Germaansche klankverschuiving Indogermaansche klanken onderhevig zijn, dus een systeem van tenues en mediae, geaspireerd en niet geaspireerd, maar geen spiranten, staat aan de latere verschuivingen een Germaansch systeem bloot, waarin geen

1) Verwendung des Gerundiums und des Participium Praesentis im Altfranzösischen, dans Zeitschr f. rom. Philologie, X, 1886, p.p. 526-554.

2) op. cit., p. 41. 
aspiraten voorkwamen, daarentegen vele spiranten, zoowel stemlooze als stemhebbende. Voor de beide jongere talen onderling verschilt het punt van uitgang hoofdzakelijk hierịn, dat tusschen de Oergermaansche en de Hoogduitsche verschuiving de Westgermaansche veranderingen liggen. Maar principieele wijzigingen in het consonantensysteem waren daardoor niet ontstaan.

Op Skandinavisch gebied vinden wij nu de volgende ontwikkeling.

1. Stemlooze spiranten. $h$ is strottenhoofdspirant gelijk in de overige dialecten; bewaard is zij an het begin. In de periode, waarmee wij hier te maken hebben, is geen enkele velare $h(x)$ bewaard; de assimilaties aan andere consonanten zijn ouder.

$f$ en $b$ zijn reeds vroeg in tonende omgeving in $\delta$ en $\delta$ overgegaan; een zeer gewoon verschijnsel.

$p$ aan het begin is $t$ geworden. Zoo in de drie talen (niet in het IJslandsch). Deze overgang had ongeveer in de $14 \mathrm{e}$ eeuw plaats. Got. preis, de. tre; g. ping. de. ting. Dat de positie aan het begin eener betoonde syllabe de oorzaak is, blijkt uit zwaktonige woorden : on. pann $>$ de. den on. $p a>>$ de. da. De waarschijnlijke ontwikkeling is $p>\delta>d$.

II. Tenues. $k t p$ zijn, insgelijks in de drie talen, aan het begin van toonsyllaben tot scherpe aspiraten geworden. De spelling $k t p$ is bewaard. Ook de $t$, die aan het begin van toonsyllaben uit $\boldsymbol{p}$ ontstaan is, doet hieraan mee. Dus: kop ting pot, spreek khop thing phot. Bij $t$ gaat de verschuiving in vele gevallen, zelfs bij gesoigneerde uitspraak, tot affricaat $t s$; op het tooneel van het Kongelige Teater in Kopenhagen kan men hooren tsro, 'trouw'.

De verbindingen $s t s p$ sk worden niet geaspireerd. Dit geheel als in het Oergermaansch, waar idg. st sp sk bewaard zijn, en in het hd., waar echter mouilleering plaats heeft.

$\mathrm{Na}$ vocalen in het midden en aan het einde is de ontwikkeling der tenues eene andere. Maar hier staat het Deensch met enkele Noorweegsche dialecten der zuidkust alleen. Zweedsch, Noorweegsch, IJslandsch behouden in deze positie de tenues. De tenues worden eerst tonend, daarna spirantisch; ten slotte kunnen zij in semivocalen overgaan en zelfs geheel verdwijnen.

Dus: $k>g>g>u(i)(>-)$.

$p>b>b>u(>-)$.

$t>d>\delta>i(>-)$. (Voorbeelden zie beneden).

III. Mediae en zachte spiranten.

1. Mediae waren er $a$ aan het begin, $b$ na nasalen, $c$ in gemitatie.

$a$. De mediae aan het begin worden in het de. stemloos, gaan dus over in tenues met niet zeer sterke articulatie. Men behoudt echter op uitsluitend etymologische gronden de spelling $b \quad d g$ : bror datter gammel. De klanken vallen samen met $p t k$, voorzoover deze niet tot aspiraat verschoven of verzacht zijn; dus $g$ in gammel als $k$ in bank.

b. De media na nasaal is daaraan geassimileerd: sand (spreek san), lam $(<$ lamb), ting (d. i. tin). Als $b \mathrm{~g}$ in 't Westgermaansch.

c. De dubbele mediae $b b \mathrm{~g} g$ zijn stemloos geworden (als aan 't begin): gubbe ligge. $d d$ daarentegen is spirantisch todde [tåð]. Dus vallen $b b \mathrm{gg}$ samen met $p p$ kk: hoppe, takke. 
2. In de overige posities heeft men van ouds de zachte spirans. Deze valt samen met die, welke in het midden en aan het einde van het woord uit tenuis ontstaat. Ze kan semivocaal worden en zelfs verdwijnen.

Voorbeelden voor beide:

labiaal : l $\phi b e$ 'loopen', klankwettig met $w$ [waarvoor de spelling is $v$ ], wat ook dikwijls gehoord wordt, maar thans meest met (stemlooze) $b$ onder den invloed van dialecten, die $p$ niet verzachten; abe 'aap' (evenzoo), leve, give, due, 'duif' (wegval) stue (hd. stube); bij de labialen bestaat dus in de voor beschaafd geldende uitspraak nog verschil tusschen etymologische tenuis en spirans in het midden); - dentaal: $s \phi d$, 'zoet' (d. i. $s \phi \delta)$ blфd (ठ $\langle t$ ), fader en far (oude ठ), compar. en superl. tiere tiest (neutr. tidt, dus $ठ\rangle-)$; - velaar: tage ta $(\langle$ taka), uge ( $g$, spirantisch $\langle k$ ), krave $(v<g)$, lov $(v<g)$, sade ( sagde), gnave, 'knagen', gavn (< gagn) enz.

Alvorens nu de vraag te stellen, welk licht van deze verschijnselen over de analoge in het Oergermaansch en het Hoogduitsch kan uitgaan, is het hier de plaats om een woord te zeggen over de vele verklaringen, die in den loop der laatste honderd jaar voor deze laatste gegeven zijn. Het ligt niet in mijn bedoeling, alle hypothesen, te beginnen met de romantische, die op zeer bijzondere eigenschappen van het Germanenkarakter bouwt, te eindigen met die, welke de verklaring zoekt in de overname eener Indogermaansche taal door een niet-Indogermaansche bevolking, de revue te laten passeeren. De meeste oudere theorieën hebben nog slechts waarde voor de geschiedenis van het onderzoek; een goed overzicht vindt men in een opstel van H. Meyer in het 45 e deel der Zeitschr. f. d. Altertum. Maar toch wil ik even stilstaan bij de meening van Meyer zelf en bij die van Feist in het $36 \mathrm{e}$ deel der Beiträge. Het eerst bij deze laatste. Feist is het, die zoowel de Germaansche als de Hoogduitsche klankverschuiving toeschrijft aan de overname eener Indogermaansche taal door eene autochthone bevolking. Deze bevolking zou de klanken der vreemde taal niet juist hebben kunnen weergeven en daarvoor de naastbijgelegen klanken van haar eigen taal gesubstitueerd hebben. I $k$ heb hiertegen twee bezwaren; het eene betreft de uitwerking der gedachte, het andere is van principieelen aard. Bij de lezing van Feist's opstel krijgt men aanvankelijk den indruk, dat hij niet slechts de verschijnselen der beide klankverschuivingen maar ook een reeks klankovergangen in andere Indogermaansche talen niet alleen onder één gezichtspunt wil brengen maar bovendien op één oorzaak wil terugvoeren. Van die poging komt echter ten slotte niets terecht. Want zelfs voor de twee klankverschuivingen maakt hij twee zeer verschillende rassen - het eene door hem als brachukephaal, het andere als dolichokephaal gekarakteriseerd - verantwoordelijk. Maar op die wijze wordt er niets verklaard. Waar telkens een ander ras aan het werk is, vraagt men zich af, waarom beide rassen precies op dezelfde wijze te werk moesten gaan, waarom beide de tenues tot spiranten, de mediae tot tenues verschuiven en niet één van beide althans in een enkel punt eens den omgekeerden weg is gegaan. Maar bovendien lijdt de hypothese aan eene fout, die ook de andere hypothesen aankleeft, namelijk het gewilde zoeken naar eene verklaring, die buiten het leven der taal zelve gelegen is. Natuurlijk is de geschiedenis van een volk 
van beteekenis voor zijne taal, maar waar men zulk een verband niet kan aantoonen, daar zweven alle vermoedens in de lucht. En dat voor een reeks consequent doorgevoerde klankovergangen een ethnologische verklaring de eenig mogelijke zou zijn, laat zich niet beweren. Wij kennen wel meer zulke overgangen op groote schaal, die wij slechts half verstaan, maar waarvan het duidelijk is, dat zij met de ethnologie niets te maken hebben. Neem bv, den $i$-umläut. De neiging daartoe begrijpen wij zeer goed: een niet palatale vocaal wordt voor een volgende $i$ gepalataliseerd, - maar eeuwen lang konden een $a$ en een $a$ en een $\boldsymbol{u}$ vóór een volgende $i$ staan, zonder gepalataliseerd te worden, tot in een bepaalde periode bij een groep nauw verwante volken, die echter niet langer één taal spraken, die palatalisatie op gaat treden. Die volken woonden uiteen; hun geschiedenis was verschillend; indien sommige hunner in die dagen of kort te voren al vreemde elementen hadden opgenomen, dan gold dat toch niet van alle, en zeker niet van alle in gelijke mate of op dezelfde wijze. Hier verbiedt de geschiedenis ons, zulke hypothesen te maken, maar als nu eens die umlauten reeds in de oudste bronnen voorkwamen en ook het Gotisch dezelfde umlauten vertoonde, wat zou ons dan verhinderen te beweren, dat die umlaut gemaakt was door een ras van oerbewoners, die met geen mogelijkheid $a$ konden spreken, wanneer in de volgende syllabe een $i$ stond, en er dus maar $e$ van maakten? Wij hadden dan precies evenveel recht tot deze conclusie als nu tot eene soortgelijke omtrent de klankverschuiving. En toch zou zij onjuist zijn.

Over Meyer's opstel wil ik slechts zeggen, dat zijn bergenhypothese mij zeker niet waarschijnlijker voorkomt dan Feist's rassenhypothese, ja, nog veel minder waarschijnlijk, daar zij veel fantastischer is. Hier wordt maar praehistorie uit het niet geschapen, om uit deze schepping dan weer de verklaring af te leiden, die de schrijver hebben wil. Daarentegen heeft Meyer gelijk, waar hij de zaak van de phonetische zijde aanpakt. Want constateeren, wat er feitelijk gebeurd is, is de eerste stap op den weg naar eene verklaring. En al kan ik ook Meyer's definities der phonetische overgangen niet tot de mijne maken, toch zal ook ik met zulke definities beginnen. Waar ik tevens de historie te hulp roep, zal ik echter niet vragen naar volksverhuizingen in voorhistorischen tijd, maar naar de latere, bekende taalgeschicdenis. De vraag waarom het te doen is, luidt: zijn de verschijnselen in de jongere talen voortzettingen van hetzelfde proces, dat in het Oergermaansch heeft plaats gehad, of zijn zij iets anders? In het eerste geval zal de oorzaak ook dezelfde zijn, en dan vervallen niet alleen de psychologische verklaringen der romantiek maar ook de praehistorische der neoromantiek.

In het Oergermaansch vinden wij de volgende veranderingen der mutae:

A. Klankverschuiving:

1. aspiratie der tenues ${ }^{1}$ ): toename van luchtdruk, misschien ook sterker mondarticulatie, waardoor de sluiting langzamer in volledige opening overgaat.

1) Dit stadium is niet overgeleverd maar wordt door velen, naar mijn meening met recht, als overgangsstadium aangenomen. Als een sterk argument kan gelden de gelijke behandeling der tenues en der tenues aspiratae, voorts de omstandigheid, dat ook de zachte spiranten evenals de scherpe - uit aspiraten zijn ontstaan. 
2. verschuiving der zachte en scherpe aspiraten tot spiranten: toename van luchtdruk.

3. mediaverschuiving: toename van mondarticulatie en luchtdruk; verlies van stemtoon.

B. Verner's wet: toename van stemtoon, maar slechts onder bepaalde omstandigheden (dus beperkt).

Als karakteristieke eigenaardigheden der klankverschuiving openbaren zich : 1. vermindering van stemtoon (een heele groep (3) verliest hem, en in geen groep ontwikkelt zich een nieuwe). 2. vermeerdering van lichtdruk, en deels, daarmee direct samenhangend, versterking van mondarticulatie.

In het Hoogduitsch vinden wij:

A. Klankverschuiving:

1. tenuisverschuiving tot aspiraat (als oergerm. 1).

2. verschuiving van deze aspiraat tot spirans (als oergerm. 2. Een zachte aspiraat was er niet, kon dus ook niet verschoven worden).

3. mediaverschuiving (als oergerm. 3. Deze heeft, gelijk uit de geringere geographische uitbreiding blijkt, ook later plaats dan 1 en 2, evenals in het oergerm., waar het uit de behandeling van jongere geminaten als in ndl. lok, huppelen, hd. schnitzen blijkt).

B. Overgang van $b$ langs $\delta$ in $d, d$. i. overgang van een beperkt aantal toonlooze spiranten in tonende en daarna in mediae. Chronologisch van de gevallen onder A onderscheiden.

In het Skandinavisch:

A. 1. tenues worden harde aspiraten (als oergerm. 1).

2. de in het Deensch veelvuldig voorkomende uitspraak van $t$ als affricaat $(t s)$, een stap op den weg van oergerm. 2. (Zachte aspiraten waren en zijn er evenmin als in het Westgermaansch).

3. mediaverschuiving: de mediae worden stemloos (als oergerm. 3; ook later dan 1, zooals blijkt uit de geringere geographische uitbreiding).

B. Verzachtingen op Deensch gebied onder bepaalde omstandigheden (maar op groote schaal).

De overgang $b>t$ aan het begin berust op verschuiving van articulatieplaats en behoort dus niet hierbij ${ }^{1}$ ).

Beschouwen wij vooreerst de onder A genoemde overgangen, d. w. z. de veranderingen, die tot de germ. klankverschuiving behooren, en hunne correlaten in het hd. en het skand., dan blijkt, dat het oude proces zich in de jongere taal tweemaal herhaalt, en wel in hoofdzaak op volkomen gelijke wijze. De afwijkingen verklaren zich uit de verschillende consonantensystemen, die aan de verschuivingen onderworpen geweest zijn, en voorts uit het chronologisch verschil.

De belangrijkste afwijkingen vinden wij bij verandering 2 , waar in de beide jongere talen de verschuiving der mediae aspiratae ontbreekt, omdat er geen mediae aspiratae waren. De tenues aspiratae, die secundair aanwezig waren - resp. zijn -, zijn in het hd. wel degelijk verder verschoven, ofschoon

1) De verandering bestaat in het terugtrekken van de tong. De interdentaal is supradentaal geworden, en daarbij ligt sluiting voor de hand, al is ze niet juist noodig. 
het eindpunt niet in alle gevallen bereikt is; in het skand., waar deze aspiratae jonger zijn, is hun verdere verschuiving niet ver gevorderd maar wel begonnen.

Wat verandering 1 en 3 betreft, hier laten zich in de jongere dialecten chronologische verschillen constateeren, samenhangend met de positie der consonanten, verschillen, die misschien ook voor het oergerm. eenmaal bestaan hebben maar hier dan weer verloren gegaan zijn tengevolge van de consequente doorvoering der verschuiving. Voor de tenues onderscheiden wij in hoofdzaak de volgende posities: 1 . aan het begin; 2 . in het midden en aan het einde; 3. in geminatie. Hier wijken nu het hd. en het skand. van elkander af. In het hd. is de positie in het midden en aan het einde die, waarin de verschuiving het verst gegaan is - tot spirans; men moet dus aannemen, dat zij hier ook het eerst begonnen is. Aan het begin en in geminatie is slechts de affricaat bereikt. Anders in het skand. Hier is de verschuiving tot aspiraat aan het begin over de drie landen verbreid. Maar in het midden en aan het einde is dit niet het geval. Voor het de. mag men aannemen, dat in deze posities de verzachtingen ouder zijn dan de aspiratie; $p t k$, die tot tonende spiranten geworden waren, konden daarna niet meer aspiraat worden. In de weinige gevallen, waar de tenuis aan het einde bewaard is, - wanneer zij $\mathrm{nl}$. een etymologische geminaat is, als bv. in kat, -- is geaspireerde uitspraak niet zeldzaam. Daarentegen is de geminaat in het midden van het woord niet geaspireerd: flytte, hoppe, bakke ('heuvel'). De verschuiving aan het begin is hier dus zonder twijfel de oudste.

Wat overgang 3, de mediaverschuiving betreft, bestaan de verschillen tusschen hd. en de. voornamelijk in het verschillende punt van uitgang. Voor het de. laat zich de positie, waarin de media voorkwam, precies bepalen, voor het hd. is dit moeilijker. In het oudere skand. komt de media voor aan het begin en in verdubbeling, en in beide gevallen heeft de verschuiving plaats. In het hd. loopen de dialecten niet alleen sterk uiteen, maar de behandeling van $b \boldsymbol{d} g$ is ook zeer verschillend; de overgang $d>t$ heeft een ruimer gebied $\operatorname{dan} b>p$, en deze ruimer $\operatorname{dan} g>k$. Dit wijst op oude verschillen in de verdeeling van spirans en media. Maar zooveel is toch duidelijk, dat ook hier aan het begin en in geminatie de media het vroegst optrad, en dat althans in het Opperduitsch de 3 mediae verschoven zijn. Tusschen het skand. en het hd. bestaat verder nog deze overeenstemming, dat de mediaverschuiving over een enger gebied verbreid is en daardoor toont jonger te zijn dan de tenuisverschuiving. Van het oergerm. dat ook hier consequent is, wijken beide genoemde talen door deze beperking af.

Ons onderzoek bevestigt den nauwen samenhang tusschen de drie reeksen van verschijnselen ten volle, en wij hebben dus ook het recht, naar een gemeenschappelijke oorzaak te zoeken, die dan natuurlijk niet in de veranderlijke uitwendige geschiedenis der volken maar in het karakter der taal zelve gelegen moet zijn. Waar wij nu vinden vermeerdering van luchtdruk en verlies van stemtoon, daar is de eerste vraag, welke van deze twee dingen primair is. Meyer dacht het eerste; hij spreekt van een versterkten luchtstroom, die de stembanden uiteendrijft, en deze versterking van den luchtstroom schrijft hij an zwaarder longenbeweging toe, die weer het gevolg 
moet zijn van het bergen klimmen. Ik voor mij geloof niet aan zwaarder longenbeweging maar meen, dat de grootere afstand der stembanden primair is. Daardoor werd bij gelijken aanvoer van lucht de luchtdruk in de mondholte van zelf sterker 1 , en op deze sterkeren luchtdruk kunnen de spieren op tweeërlei wijze reageeren: of de mondarticulatie wordt versterkt, en de media wordt tenuis - wat in het de. nog niet geheel het geval is -, ò als de spanning dezelfde blijft, dan wordt de sluiting geopend, en men krijgt in plaats van de tenuis eerst een aspiraat, dan een spirans. Zóó bij de tenuisen aspirataverschuiving.

Aan die mindere spanning der stembanden kan men ook andere klankovergangen toeschrijven, en wel in de eerste plaats het optreden van ondistincte vocalen in zwaktonige syllaben, lang met behoud van een deel hunner kleur door mondarticulatie, maar ten slotte ook met verlies van deze.

Wat is nu de oorzaak van deze verminderde spanning der stembanden? Wij behoeven niet lang naar het antwoord te zoeken. Het is gelegen in het sterke expiratorische accent van het Germaansch. In zekeren zin is het onjuist, aan sommige talen een expiratorisch, aan andere een muzikaal accent toe te schrijven. Maar ook slechts in zekeren zin. ledere syllabe in iedere taal heeft zoowel haar expiratiedruk als haar toonhoogte, en zóó opgevat, heeft iedere taal een expiratorisch èn een muzikaal accent. Maar wat aan het accent van een taal zijn karakter geeft, is het terrein, waar de groote verschillen zich voordoen. Waar het verschil in expiratiedruk tusschen verschillende lettergrepen sterk is, daar valt het expiratorisch accent in het gehoor, daar gaat het domineeren, daar wordt het een factor van invloed bij de verdeeling van den zin, daar wordt het van waarde voor de juiste opvatting der beteekenis van het gesprokene. Het expiratorisch accent kan zoodoende een rol spelen, die in een andere taal aan het muzikaal accent, d. w. z. aan de wisseling in toonhoogte, toekomt, en het is ook denkbaar, dat in eene taal, waar het eerstgenoemde accent zich sterk ontwikkelt, het een deel der functies van het laatstgenoemde overneemt. Wat zal dan het gevolg zijn? Dat het muzikale accent verwaarloosd wordt. Het is er nog wel door de traditie, maar daar het voor den zin geen beteekenis meer heeft, treedt het op den achtergrond en kan langzaam uitslijten, zooals dan ook in de meeste Germaansche talen gebeurd is. De stembanden worden nog wel gespannen bij de vocalen en de stemhebbende consonanten, maar aan deze spanning wordt minder aandacht besteed dan vroeger, toen zij ook voor woord- en zinsbetoning van waarde was. En het gevolg is vermindering, en in bepaalde gevallen verlies, van stemtoon. De stembanden blijven hun bewegingen doen, maar het geheele instrument is iets lager gestemd. Zóó is het in het Oergermaansch gegaan, en daar dit domineeren van het expiratorisch accent voortduurt en zelfs toeneemt, herhalen zich de verschijnselen. Het is dan ook begrijpelijk, dat het Deensch, waar de Skandinavische klankverschuiving het sterkst ontwikkeld is, ook die skand. taal is, die de minste toonbeweging kent.

1) Tegen de verbreide maar onjuiste meening, dat de expiratiedruk bij het spreken geheel of in de eerste plaats door de ademhalingsorganen geregeld vordt, polemiseert Jespersen reeds in 1904 in zijn Lehrbuch der Phonetik p. 115, onder verwijzing naar eene theorie van Forchhammer van 1896. 
lk kom nu tot de verschijnselen, die ik voorloopig onder letter B heb samengevat en zal de vraag bespreken, of ook deze eene verklaring uit een gemeenschappelijk beginsel vereischen 1 ).

Volgens Verner's wet treedt een tonende spirans op in plaats van een toonlooze, indien in het Indogermaansch de hoofdtoon niet onmiddellijk voorafging. In vele gevallen volgde de hoofdtoon onmiddellijk. Hoe is dat te verstaan? De stemtoon van den volgenden klinker deelt zich mee aan den voorafgaanden medeklinker. Hoe sterker de volgende klinker gestemd is, des te grooter is de kans, dat reeds bij den voorafgaanden medeklinker de spanning bereikt is, die noodzakelijk is, om aan dien medeklinker stemtoon mede te deelen. De klinker in questie moet dus hoogen muzikalen toon gehad hebben. Maar een voorafgaande klinker met indog. hoofdtoon had die uitwerking niet. Bij het slot van zulk een klinker was de spanning dus reeds verminderd; de klinker was gedaald. De overgang van scherpe spirans in zachte hangt dus samen met een muzikaal, niet met een expiratorisch accent. En daarom geloof $i k$, dat men niet behoeft te zeggen, dat Verner's wet ouder is dan de Germaansche accentuatie. Men kan zich zeer goed voorstellen, dat het Germaansch den sterksten druk op de eerste syllabe had, toen het Indo. germaansche muzikale accent nog wisselend was, - en dit accent is voldoende voor Verner's wet. Een muzikaal hooge toon op expiratorisch zwaktonige syllabe komt ook later in het Germaansch voor; nog heden is dit 0 . a. het geval zoowel in de Zweedsche rijkstaal als in de dialecten.

Men moet zich dus de toonbeweging van een vorm als "baupa, waaruit got. baup ontstond, aldus voorstellen: "baupa; de stem daalde gedurende de eerste syllabe, en deze daling werd in de tweede lettergreep voortgezet.

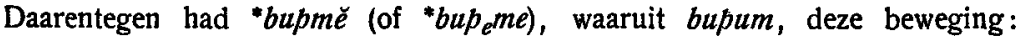
- bupmér2). De stijging begon op de grens van $u$ en $p$. Die toonbeweging is vereenigbaar en was in het Oergerm. vereenigd met een decrescendo over het geheele woord "bup(e)mé. Dit decrescendo heeft op den duur ook een neergaande toonbeweging ten gevolge gehad; alleen zóó verklaart zich de apocope van den slotklinker.

De opkomst van het Germaansche accent heeft men zich niet voor te stellen als een accentverplaatsing, want het oude accent, van een andere natuur dan het nieuwe, kan, gelijk wij zagen, zeer goed daarnaast bestaan. Een expiratorisch accent heeft, waar het opkomt, de neiging, de eerste syllabe te kiezen, want het berust op een overvloed van energie, die bij het spreken van het woord of de groep woorden verbruikt wordt. Kenmerkend voor het Germaansch is slechts het sterke op den voorgrond treden van zulk een expiratorisch beginaccent, dat waarschijnlijk in zijn beginselen reeds uit Indogermaanschen tijd dagteekent, - eene vraag, wier behandeling trouwens buiten ons bestek ligt. Het verlies van het oude accent is slechts een gevolg, dat langzaam intreedt, en misschien nog niet geheel volbracht is. Want er spreekt

1) Gemeen hebben zij, dat stemlooze medeklinkers stemhebbend geworden zijn.

2) Indien de vorm drielettergrepig was, waarover verschillende meeningen mogelijk zijn, dan had in het idg. de derde syllabe den - muzikalen - hoofdtoon. De stijging moet echter bij de twreede begonnen zij̉n; alleen zóó is de overgang $\boldsymbol{\rho}>\partial$ begrijpelijk. 
veel voor, dat de hooge toon in Zweedsche eindsyllaben, waarover ik reeds sprak, in vele gevallen een voortzetting van dit oude accent is.

Op Hoogduitsch - trouwens ook op Nederduitsch en Nederlandsch gebied hebben wij hierboven als een schijnbaar analogon van Verner's wet genoemd den overgang van $p$ langs $\delta$ in $d$. Deze overgang heeft echter met die wet niet meer gemeen dan het stemhebbend worden van een stemlooze spirans in sternhebbende omgeving. Met de toonbeweging van het woord heeft de overgang niets te maken; hij heeft ook in alle posities plaats. Hij staat ser op één lijn met den overgang van $f$ in $v$ in het Nederlandsch. De verdere ontwikkeling $\partial>d$ is een herhaling van den gelijken overgang in het Westgermaansch. De $b$ staat in de jongere germ. talen in hooge mate aan wijzigingen bloot. In het hd. zijn in het algemeen bij de dentalen de veranderingen het sterkst. Maar ook het jongere Skandinavisch - behalve het IJslandsch - ruimt $\boldsymbol{p}$ op; immers wij zagen, dat daarvoor $t(t h)$ optreedt.

Ten slotte moet ik nog iets over de Skandinavische verzachtingen zeggen: tenues in het midden en aan het einde worden in het Deensch tot zachte spiranten. Daarbij komen een reeks voorbeelden aan het einde van zwaktonige syllaben in het Noorweegsch en IJslandsch, daaronder reeds oude, als $i{ }^{\gamma}$ voor it. Hier is zeker niet het optreden van den stemtoon primair; deze blijft zelfs tamelijk zwak, maar primair zijn de zwakke druk en de daarmee samengaande zwakke articulatie, het gevolg van het sterke verbruik van energie aan het begin van het woord. Vandaar dan ook de bijna volkomen vervluchtiging van vele consonanten. Het verlies van articulatie en druk heeft hier de ontwikkeling van eenigen stemtoon tot gevolg. Wij hebben hier dus met een verschijnsel te doen, dat samenhangt met het expiratorisch accent en de beginbetoning en dus nauwer verwant is met de klankverschuiving dan met Verner's wet, die juist op het oudere muzikale accent berust. Maar een paralel van de klankverschuiving is het niet. Het is een verschijnsel, dat slechts op dezelfde laatste oorzaak terug te voeren is. Bij ons komt uit dezelfde praemisse - verlies van energie - juist een omgekeerd resultaat voor den dag: brood met $t$; verlies van stemtoon en dientengevolge verscherping der media.

Amsterdam.

R. C. BOER.

\section{ROMANTISCHES IN SCHILLERS DRAMEN.}

Der 10. Band des Goethe-Jahrbuchs (1889) brachte unter dem Titel Classiker und Romantiker einen kurzen aber gehaltvollen Aufsatz von Jakob Minor, der, manches mehr andeutend als ausführend, von dem Verhältnis Goethes und Schillers zur Frühromantik auf Grund der Quellen ein Bild entwarf, das bestimmt war, die landläufige Auffassung, als seien klassische und romantische Dichtung unvereinbare Begriffe, zu berichtigen. Minor ging dabei von der Frage aus, ob der Mißerfolg der Propyläen der romantischen Zeitströmung zuzuschreiben sei. "Diese Meinung”, sagt er (S. 215), „ist historisch nicht zu rechtfertigen und darum falsch. In den Jahren 1798-1800, während welcher 